\title{
O Brasil e as Nações Unidas
}

\section{RONALDO MOTA SARDENBERG}

A COMEMORAÇÃo do cinqüentenário das Nações Unidas convida à reflexão sobre seu papel, em todos esses anos, na cena internacional e sobre suas perspectivas para o futuro. Sugere, também, a possibilidade de passarmos em revista as linhas gerais da contribuição que o Brasil pode prestar à Organização nesta fase na qual se reorganiza de maneira dramática a macroestrutura mundial, se reordenam as formas tradicionais de interação dos Estados e emergem novos atores internacionais, sob o impulso dos avanços nas tecnologias de comunicação.

O presente colóquio, em tão boa hora promovido pela Universidade de São Paulo, atraiu a participação de alguns dos maiores especialistas brasileiros na temática das Nações Unidas, o que vem atestar o renovado interesse nacional pelas questões multilaterais. Fico especialmente agradecido ao Instituto de Estudos Avançados por haver me proporcionado a oportunidade de retornar à Universidade de São Paulo e de juntar-me a esses especialistas, de tanto renome, na abertura deste colóquio.

Se me fosse permitida mais uma palavra de cunho pessoal desejaria saudar especialmente a presença do Embaixador Saraiva Guerreiro, meu primeiro professor dos assuntos das Nações Unidas, ainda no Instituto Rio Branco. Ao longo de minha carreira, não deixou o Embaixador Guerreiro de me proporcionar oportunidades para que me aprofundasse na temática das Nações Unidas. Assim, tive a honra de assessorá-lo em questões de desarmamento, em quatro sucessivas sessões da Assembléia Geral e, mais adiante, por nove anos como seu conselheiro, quando exerceu sucessivamente as funções de Secretário Geral e Ministro de Estado das Relações Exteriores. É inestimável a contribuição dada pelo Embaixador Guerreiro à atuação do Brasil na ONU, desde os primeiros anos da Organização.

Membro fundador, o Brasil nunca foi um espectador neutro, mas sim um participante ativo nos trabalhos das Nações Unidas. Sete vezes integrante do Conselho de Segurança - número recorde juntamente com o Japão - inclusive duas vezes em anos recentes, quando os processos de transformação da ordem internacional já se haviam desencadeado, o Brasil acumulou um conhecimento privilegiado acerca dos modos de funcionamento dos círculos decisórios mundiais. O Conselho, um dos órgãos principais da ONU, encarregado - como diz a Carta da responsabilidade primária pela manutenção da paz e da segurança internacionais, certamente espelha o funcionamento desses círculos no plano multilateral. 
Igualmente, o país sempre teve atuação de vanguarda na Assembléia Geral, no Conselho Econômico e Social, em suas comissões funcionais e, ainda, nas grandes conferências internacionais, o que lhe permitiu exercitar as práticas parlamentares e aproveitar as oportunidades políticas inerentes à diplomacia multilateral.

Como todos os Estados-membros, o Brasil sabe que o desempenho das Nações Unidas incorpora tanto realizações quanto desapontamentos, tanto esperanças, quanto frustrações. Muitos dos sonhos de 1945 se esfumaçaram e se perderam nos sucessivos embates da política internacional e as tentativas recentes de revivê-los não resistiram às pressões dos eventos contemporâneos.

A atuação das Nações Unidas só é ininteligível a partir do quadro da evolução da ordem internacional. A relação entre a ONU e as realidades políticas não é, porém, mecânica. Expressa mesmo uma tensão dinâmica entre as funções das Nações Unidas como produto da ordem internacional e as que têm como possível veículo de sua transformação.

Há momentos e temas em que a ONU pode estar à frente na realidade política mundial e criar condições para a promoção da reforma de status quo e da correção de injustiças, mesmo as amparadas pelos esquemas dominantes de poder. Assim ocorreu na luta anticolonial e na campanha contra o apartheid na África do Sul. Em outras vertentes, contudo, a ONU vai representar exatamente a operação dos esquemas de poder, como ocorreu em todas as fases da Guerra Fria, inclusive as últimas. O papel da ONU é, portanto, variável, e tanto pode exprimir as aspirações maiores da humanidade quanto servir de suporte ao congelamento do poder.

A agenda das Nações Unidas evolui no tempo e a definição de seus rumos constitui desafio perene à capacidade política e de articulação diplomática dos Estados-membros. O espírito dominante em 1995 não poderia permanecer o mesmo de 45, embora no essencial a Carta das Nações Unidas seja a mesma: seus Propósitos e Princípios ainda representem a mais eficaz garantia de paz e de segurança internacional à disposição dos Estados, e seus mecanismos decisórios continuem, no essencial, intocados.

As Nações Unidas, desde a sua fundação, ocupam posição central no sistema internacional (1). Projetados para impedir o retorno do flagelo da guerra, os mecanismos de segurança coletiva que emergiram de São Francisco se viram paralisados, durante décadas, por um terrível complicador: a guerra fria. Distorceu-se, assim, a evolução institucional da Organização, com conseqüências que se fazem sentir até hoje, em termos, por exemplo, de procedimentos e composição do Secretariado e de certos órgãos.

Não farei nesta oportunidade a recensão do que foram as Nações Unidas nestes 50 anos de existência. Mas desejaria referir-me a três pontos: 
- a agenda da Organização, que ultrapassa em muito as questões de segurança internacional, foi capaz de incorporar o exame de vastos temas que simplesmente eram desconhecidos ou inexistiam quando se reuniu a Conferência de São Francisco, como o uso da energia nuclear, o desenvolvimento econômico, o meio ambiente e as atividades no espaço exterior, para citar apenas alguns exemplos;

- a virtual universalização das Nações Unidas é uma de suas maiores conquistas políticas e um dos fatores definidores da própria ordem internacional: em 1945, a ONU tinha 51 membros fundadores; em 1960, 100; em 1984, alcançava 154; em 1991, 159; e hoje, um total de 185. A diversidade política e cultural é um dos traços dominantes da Organização, que, assim, ganha inédita representatividade mas, ao mesmo tempo, é forçoso reconhecer a heterogeneidade dos Estados-membros constituir uma das razões que dificultam a agilização dos trabalhos da Assembléia Geral, hoje reconhecidamente emperrados.

- o fim da Guerra Fria permitiu ao Conselho de Segurança um nível de atividades e um prestígio internacional que não conhecia praticamente desde a fundação das Nações Unidas (em 1990, foram aprovadas pelo Conselho 37 Resoluções; em 1991, 42; em 1992, 74; em 1993 e em 1994, 76. Por um breve momento, sob o estímulo do conflito do Golfo de 1991 e do conseqüente ativismo do Conselho, chegou a esboçar-se um movimento, nas Nações Unidas, em direção ao supranacionalismo que a Agenda para a Paz tentou operacionalizar e ainda um novo enfoque político que utilizou o chamado dever de ingerência como bandeira principal, sob a liderança das principais potências ocidentais. Depois das experiências da Somália e da Bósnia e tendo presente a crise financeira da Organização, certamente predomina uma atitude mais sóbria e mais consciente das limitações políticas e psicológicas que pesam sobre o uso internacional da força, mesmo quando multilateralizado e autorizado pelo Conselho de Segurança.

O Brasil aproxima-se das Nações Unidas plenamente ciente dos fatores básicos que nos vinculam à comunidade internacional, a saber: país, antes de mais nada, dedicado à paz mundial e da região, de larga tradição de convivência fraterna com seus vizinhos e de promoção de relações harmoniosas entre os Estados, com reconhecida fidelidade aos compromissos assumidos na Carta das Nações Unidas.

Conhece e vive o Brasil também os traços que o distinguem entre as nações, tanto no plano interno, quanto no que lhe delineiam o perfil de atuação internacional, como suas dimensões demográfica, territorial, política e econômica; a variedade étnica de seu povo; a heterogeneidade de sua estrutura econômica e social; as discrepâncias na distribuição da renda e, no nível externo, sua profunda ancoragem regional e sub-regional, projeção sul atlântica; e interesses como global trader, crescentemente, como ator global. O Brasil sempre esteve entre os países voltados para a mudança nas Nações Unidas; sempre soube dar sua contribuição ao esforço para fazê-las mais abertas e eqüitativas, mais transparentes e sensíveis aos reclamos de nosso tempo. 
Tendo em vista o atual quadro internacional, as tendências dominantes nas Nações Unidas e as características da inserção internacional do Brasil, talvez pudéssemos imaginar uma proposta tentativa de agenda brasileira com relação às Nações Unidas para os próximos anos. Essa agenda teria de recolher o que há de experiência válida e o que deve haver de inovador na postura brasileira. Teria de estar muito atenta à imbricação do Brasil em sua própria região, a América Latina, assim como a sua inserção na política e na economia mundiais. Teria de ser realista - enfrentar a cena internacional tal qual ela é, sem ilusões nem queixumes, mas ser conseqüente com nossas tradições e promover sistematicamente as aspirações da sociedade brasileira. Considerando a dificuldade da tarefa, os nove pontos a seguir têm caráter apenas tentativo e representam não mais que uma visão pessoal do que poderia ser o perfil brasileiro nas Nações Unidas a longo prazo.

Nesta época de dúvidas e incertezas, torna-se imprescindível reafirmar os Propósitos e Princípios espelhados nos artigos $1^{\circ}$ e $2^{\circ}$ da Carta das Nações Unidas. Constituem os Propósitos e Princípios a plataforma mais avançada e universal que até hoje se logrou alcançar na esfera internacional. Servem eles de embasamento à Organização, que afinal é a única agência política à disposição de todos os Estados, como tantas vezes assinalou o Embaixador João Augusto de Araújo Castro. Permitem, juntamente com o Preâmbulo da Carta, matizar e qualificar o funcionamento dos mecanismos decisórios das Nações Unidas, especialmente os relativos à manutenção da paz e da segurança internacionais.

II

Acentue-se que as Nações Unidas são o principal regulador da ordem mundial, isto é, a principal fonte de legitimação nas relações internacionais contemporâneas e têm funções fundamentais no processo de solução das diferenças interestatais. A reforma de seus processos deliberativos passa necessariamente pela confirmação do princípio da igualdade soberana entre os Estados e pelo reconhecimento do papel essencial que estes cumprem.

O sistema de relações interestatais continua a prover o quadro que organiza politicamente a sociedade internacional e as próprias Nações Unidas são constituídas de Estados-membros, não de outros atores internacionais. Apesar de esforços para diluir a territorialidade dos Estados como critério básico da presente ordem, nada indica que tal critério venha a desaparecer em futuro previsível. Por outro lado, a ninguém ocorreria argumentar que o Estado tem hoje statusidêntico ao de décadas ou séculos anteriores, dada a interpenetração das sociedades nacionais estimulada pela revolução tecnológica. Mas o reconhecimento dos poderes inerentes aos Estados constitui o primeiro passo no sentido de reorganizar o relacionamento entre eles e os novos atores internacionais nas Nações Unidas. 
Seria arriscado afirmar que a ONU caminha para um governo mundial: as chamadas tendências supranacionais ainda facilmente se identificam com interesses nacionais de Estados específicos. Nem se poderia caracterizar, a rigor, uma sociedade civil transnacional com o mesmo sentido político e jurídico das existentes sociedades civis nacionais organizadas sob a forma estatal e representadas regularmente nas Nações Unidas.

O máximo a que poderíamos aspirar nesta fase seria a plena utilização das instituições multilaterais existentes, seu aperfeiçoamento e a formação de um sistema internacional bem ordenado. Não existe, contudo, consenso sobre as modalidades de regulação do sistema, nem há condições políticas objetivas para impô-la pela força.

Em segundo lugar, poder-se-ia chegar a uma definição mais precisa das formas de convivência com as ONGs.

No plano interno, promove-se a parceria entre o Estado e elas, de modo a habilitá-las a trabalhar para a implementação do projeto nacional, com a melhor utilização de suas experiências, por exemplo, nas áreas sociais e ambientais. Durante o período do autoritarismo, prevaleceu no Brasil o modelo pelo qual as ONGs rotineiramente se dedicavam a trabalhar contra as diretivas governamentais. Essa tradição necessita ser reavaliada à luz da cultura política agora prevalecente no país. Hoje estamos todos empenhados no fortalecimento do Estado de direito, como reconhecido na Constituição, e pode-se esperar que as ONGs, como todas as instituições do país, estejam adaptadas à realidade da vigência do sistema democrático representativo. Este novo diálogo entre o Governo e as ONGs certamente teria repercussões na atuação do Brasil nas Nações Unidas.

\section{III}

A democracia é valor crescentemente presente também no plano internacional. É verdade que não alcança a ser universal e com freqüência as formalidades da democracia não se fazem acompanhar de sua substância. Mas o espírito e a prática democráticos fornecem plataformas para o diálogo e o entendimento entre as nações. Politicamente, a democracia é tão válida no plano interno quanto no internacional. Neste, opera orientada pelo menos por três vetores:

- todos os Estados, inclusive os mais poderosos, devem comportar-se de forma democrática na arena internacional;

- devem respeitar a plena operação de processos democráticos alheios à intervenção estrangeira no Estado democrático, diferentemente do que ocorreria no dominado pela ditadura, que seria uma usurpação dos poderes e das prerrogativas do povo; e, finalmente, 
- devem promover a cooperação internacional em favor do Estado de direito da participação popular, do fortalecimento das instituições democráticas e da remoção das desigualdades sociais e econômicas.

De imediato, aceitando-se que todos os Estados-membros atuam em função de seus próprios interesses nacionais, poder-se-ia buscar, na observância dos valores democráticos, a base para a melhor convivência entre eles. A democratização das relações internacionais, e das próprias Nações Unidas, tem grande interesse como princípio orientador do desenvolvimento das relações internacionais.

IV

É preciso dar, nas Nações Unidas, prioridade às opções diplomáticas. Deve-se pensar mais em diplomacia preventiva do que no uso preventivo da força (preventive deployment), o qual deve ser reservado para quando estejam esgotadas as alternativas diplomáticas. As soluções militares recentemente adotadas para problemas políticos internacionais provaram ser de pequena utilidade e eficácia.

Devem, por outro lado, ser estimuladas a expressão de aspirações e interesses de países grandes e pequenos e a acomodação dinâmica das variações do poder mundial e regional. Com vistas a formatar o futuro da Organização, será necessário ouvir todos os Estados-membros. Novos tipos de diálogo terão de ser criados, de maneira a minimizar as assimetrias entre os Estados (mas também entre os órgãos principais das Nações Unidas).

Por sua universalidade, por estar diretamente sintonizada com as preocupações dos Estados-membros, a Assembléia Geral é a verdadeira guardiã das intenções democráticas da Carta de São Francisco. A crise da Assembléia Geral é a crise da democracia na Organização. Sua desvalorização corresponde a uma tendência perniciosa a ser combatida. É preocupante o presente desequilíbrio institucional nas Nações Unidas. A Assembléia pode ser fortalecida por meio de melhor organização de seus trabalhos e da consolidação de sua agenda, pela utilização de meios e técnicas parlamentares mais modernos, por atualização e robustecimento das funções de sua Presidência, pela interpretação mais estrita e conseqüente dos poderes atribuídos na Carta ao Conselho e pela melhor utilização política de grupos regionais e de afinidade de interesses.

Nada que se possa fazer no plano da Assembléia desvaloriza a fundamental importância do Conselho na Organização e na própria ordem internacional. Seus atuais problemas são conhecidos e necessitam ser cuidadosamente atendidos. Penso especialmente em sua composição restrita, seu passado caracterizado pelo uso imoderado da faculdade de veto, suas persistentes deficiências de representatividade e seus procedimentos crescentemente opacos. 
A atitude do Brasil ao aggiornamento do Conselho e de sua composição é conhecida e foi expressa recentemente pelo presidente Fernando Henrique Cardoso. As novas realidades políticas mundiais devem ser reconhecidas e refletidas na composição do Conselho. Seus procedimentos igualmente devem ser modernizados e seu papel propriamente diplomático fortalecido, para que melhor possa se haver com a intratabilidade das questões de ordem regional e sub-regional, e até mesmo subnacional, que presentemente ocupam as atenções internacionais.

V

Convém regular de forma mais apurada as Operações de Paz das Nações Unidas. A tendência recente para o lançamento de maior número de operações (entre 1948-78 foram estabelecidas 13; de 1988 em diante cerca de 20) coincidiu com alguma confusão conceitual, de vez que o Conselho tem sido extremamente casuísta na definição dos parâmetros e mandatos que as orientam. As Operações de Paz constituem instrumento importante mas sua utilidade não é ilimitada. Parece essencial tipificá-las corretamente de modo a prevenir os equívocos políticos e militares que têm ocorrido em sua implementação. Deve-se, por exemplo, evitar sejam amalgamadas, automaticamente, as Operações dimensões a elas estranhas como o monitoramento de eleições, medidas unilaterais ou multilaterais de imposição coercitiva da paz, assistência humanitária (a propósito desta, nota-se que não existem verdadeiras perspectivas de que se possa chegar a acordo (2) em matéria de intervenção humanitária; o que está ocorrendo nesse campo é uma reforma branca da Carta, por meio de decisões do Conselho de Segurança). A questão do consentimento das partes deve ser rigorosamente regulada e observada na prática.

Ao Brasil interessa fortalecer a presença diplomática da América Latina nas Nações Unidas, com base em fatores que nos unem como a coesão política, as tradições culturais e a adesão ao Direito Internacional, além dos interesses econômicos e ecológicos que amplamente compartilhamos (3). Torna-se necessário reforçar a unidade latino-americana no plano multilateral, com base em enfoques mais sofisticados e melhor concertados que os anteriores. Está em ascensão a autoconsciência da América Latina.

Com o progresso dos processos democráticos, cada vez mais nos entendemos como uma América que além de latina é indígena, negra e mestiça (também com outras heranças étnicas), elementos estes que se combinam de diferentes formas e em diferentes proporções em cada um de nossos países.

A presença da cultura ocidental na região é demasiado óbvia para necessitar elaboração. A adesão comum aos valores democráticos deve ser a base de uma relação mais criativa e eqüitativa entre os países latino-americanos e as nações industrializadas do Ocidente, nas Nações Unidas e em outros foros. 
Embora não seja possível antecipar a forma que tomará a economia mundial - se o globalismo se tornará hegemônico ou se, pelo contrário, a tendência à regionalização sairá vitoriosa -, pode-se afirmar que o relacionamento Norte-Sul passa por transformações significativas e é necessário que o diálogo entre esses dois grandes grupos de países se desenvolva e se aperfeiçoe.

Não haveria, porém, um verdadeiro futuro para o diálogo global, caso o Norte firme uma estratégia de simplesmente promover a desagregação do Sul como coalizão parlamentar e negociadora ou de cooptar alguns países em desenvolvimento. Mesmo se o Brasil figurasse entre os escolbidos, tal estratégia não atenderia a nossos interesses dada a forte imbricação regional do país (seria difícil imaginar uma visão de futuro do Brasil que fizesse abstração do entorno regional em que se insere).

O globalismo, note-se, tem-se revelado excludente não só de grupos sociais, mas também de países inteiros. Essa tendência patológica obriga a reiteração, no plano multilateral, da validade do desenvolvimento como objetivo e um direito a ser estruturado, plataforma mínima de entendimento entre todos os países.

Neste momento em que tanta ênfase vem sendo dada ao monitoramento e controle das economias do Sul, três medidas práticas e interligadas merecem consideração multilateral:

- a operacionalização acelerada dos resultados das grandes conferências internacionais, sobre meio-ambiente (1992), população (1993), direitos humanos (1994), mulher e cúpula social (1995) e hábitat (1996), cuja realização tem caracterizado esta década. Todas essas conferências se dedicam especificamente à questão do desenvolvimento, o que leva às duas outras medidas;

- a ampliação do conceito de desenvolvimento sustentável para os plano social, tecnológico e financeiro e sua rápida conversão em políticas universalmente aceitas, conceito esse consagrado na Conferência do Rio, constitui avanço revolucionário que integra duas dimensões até então mantidas separadas, as do desenvolvimento e do meio-ambiente, e supõe a formação de ampla parceria Norte-Sul, em benefício de toda a humanidade;

- a retomada da idéia de convocar na segunda metade da década a conferência mundial do desenvolvimento para passar em revista e compatibilizar os progressos alcançados nas grandes conferências, assim como reformar a própria conceituação de desenvolvimento, levando em conta as alterações na composição orgânica do capital em escala planetária.

O relançamento do debate econômico nas Nações Unidas e a reconceituação do desenvolvimento estão na raiz da iniciativa brasileira da Agenda para o Desenvolvimento, ora em discussão na Organização. 
É necessário trabalhar intensamente em favor dos direitos humanos e das prioridades sociais. Quanto aos direitos humanos, muitos são os indícios de que uma mudança radical de mentalidades está em andamento e que se torna possível a emergência de uma cultura universal baseada na sua observância e no respeito às liberdades fundamentais. São esses efetivamente imperativos morais, independentes em si mesmos e, portanto, de quaisquer outras considerações, inclusive dos níveis de desenvolvimento dos diferentes países. Na prática, porém, os imperativos morais devem ser traduzidos em lei e o processo legislativo é claramente sensível a condicionantes de natureza sócio-econômica. O interesse internacional pelos direitos humanos deve ser acompanhado de renovados esforços de cooperação internacional no campo sócio-econômico.

Mais especificamente, novas abordagens devem permitir a estruturação da cooperação internacional para reforçar o atendimento a necessidades materiais como o bom funcionamento da política dos tribunais e das penitenciárias, a proteção dos direitos das minorias e a criação de condições sócio-econômicas que facilitem a manutenção dos estados de direito e a observância do primado da lei. A maior cooperação internacional no campo da administração da justiça, inclusive o sistema penitenciário, impulsionará os esforços no sentido de acabar para sempre com a impunidade.

Igualmente, é preciso organizar os fluxos de cooperação internacional de modo que as questões da pobreza e da exclusão social possam ser melhor enfrentadas.

\section{IX}

Deve-se evitar que progridam as tentativas de despolitização da agenda das Nações Unidas, as quais às vezes podem ser identificadas na proliferação de propostas para a discussão de temas por certo muito importantes mas que poderiam ser tratados em outros foros. A ênfase em questões ou ameaças globais muitas vezes se baseia em interesses tópicos, facilita a erosão de soberanias e abre caminho para a chamada cooperação intrusiva. Não se deveriam articular as atividades das Nações Unidas, e as próprias relações internacionais, a partir de respostas ad hoc ao comportamento dos Estados mais fracos ou excluídos que, por sua debilidade ou por adotarem políticas deliberadas, geram parte da instabilidade hoje existente.

É hora de promover nas Nações Unidas procedimentos que tomem por base os critérios da transparência, previsibilidade, eqüidade e confiabilidade em seu funcionamento e que tenham como vetor dinâmico o desenvolvimento das relações entre os Estados por meio do consentimento e do Direito das Nações. 
Notas

1 Ver, por exemplo, Adam Roberts e Benedict Kingsbury, Presiding over a divided world changing UN roles 1945-1993, International Peace Academy, 1994.

2 Idem, ibidem.

3 Ver Ronaldo Mota Sardenberg, Latina America and the United Nations, 1991.

Ronaldo Mota Sardenberg, embaixador, é secretário de Assuntos Estratégicos da Presidência da República.

Palestra feita pelo autor no Colóquio Carta de São Francisco: 50 anos depois, organizado pela Área de Assuntos Internacionais do Instituto de Estudos Avançados na Sala do Conselho Universitário da USP no dia 23 de junho de 1995. 